\title{
LAS VENIDAS DE CRISTO EN EL APOCALIPSIS
}

La venida de Cristo es generalmente comprendida por los cristianos de manera exclusivamente escatológica, o sea como algo que acontecerá una sola vez al final de los tiempos (la parusía). El Hijo de Dios vino una vez sobre la tierra hace 2.000 años en el misterio de la encarnación; y vendrá una segunda vez en la gloria al final de la historia para juzgar a los vivos y a los muertos, como lo afirma el Credo. Es lo que vemos en los textos de los evangelios sinópticos (por ejemplo, en la escena del juicio final en Mt 25,31-46) y en las cartas de san Pablo (cf. 1 Ts 4,13-17; 2 Ts 2).

A primera vista, el Apocalipsis parece confirmar esta interpretación, por el acento que pone sobre la venida escatológica de Cristo para el juicio. Sin embargo, las cosas no son tan sencillas. Un estudio más profundo revela diversas venidas de Cristo. Quisiéramos entonces estudiar la doctrina del Apocalipsis sobre las venidas de Cristo y la importancia de este tema para la vida cristiana.

\section{El verbo érjomai en el Apocalipsis}

\section{Estadísticas}

Empecemos por un estudio del vocabulario de la venida en el Apocalipsis. Este estudio se focalizará esencialmente sobre el verbo "venir" (érjomai). De hecho, hay que constatar que el sustantivo parousía está ausente en el Apocalipsis ${ }^{1}$ como también lo está el verbo "aproximarse" (eggízō),

1. Usado 24 veces en el Nuevo Testamento, está ausente de los escritos joánicos, salvo en $1 \mathrm{Jn}$ 2,28. 
que encontramos en los sinópticos, donde expresa varias veces la proximidad del reino de Dios. ${ }^{2}$ Encontramos 36 ocurrencias del verbo érjomai en el Apocalipsis, las cuales pueden ser clasificadas de la manera siguiente:

- $\quad 3$ ocurrencias en la expresión: “Aquel que es, que era y que va a venir (erjómenos)" (Ap 1,4.8; 4,8).

- 1 ocurrencia en la expresión: "Miren, [Cristo] viene acompañado de nubes" $(1,7)$.

- 7 ocurrencias en la boca de Cristo diciendo: "Vengo" $(2,5.16 ; 3,11$; $16,15 ; 22,7.12 .20)$.

- $\quad 7$ ocurrencias en imperativo: “¡Ven!” $(6,1.3 .5 .7 ; 22,17[2 x] .20)$.

- 4 ocurrencias diversas, que tienen un vínculo indirecto con nuestra búsqueda: 3,10 , que anuncia la venida de la hora de la prueba; 6,17 , que anuncia que ha llegado el gran día de la cólera de Dios y del Cordero; y 19,7, que anuncia que han llegado las bodas del Cordero.

- otras 14 ocurrencias que no tienen interés inmediato para nuestra investigación.

Encontramos también en el Apocalipsis 14 ocurrencias del verbo exérjomai, 8 ocurrencias del verbo apérjomai, 5 ocurrencias del verbo $e i$ sérjomai; su estudio muestra rápidamente que no todas tienen importancia para nuestra búsqueda, salvo (tal vez) la de 6,2. Encontramos también 6 ocurrencias del verbo hếk $\overline{\boldsymbol{o}}$; tres de ellas, en las cartas a las Iglesias $(2,25 ; 3,3[2 \mathrm{x}])$, llamarán nuestra atención.

Dada la importancia simbólica de los números en el Apocalipsis, podemos observar el dato siguiente: Cristo anuncia su venida 7 veces. Esto probablemente no es casual. Debemos, naturalmente, ver si los siete imperativos “¡Ven!” son dirigidos a Cristo.

\section{La venida del Padre}

Consideremos rápidamente la expresión "Aquel que es, que era y que va a venir". Es claramente una denominación del Padre y se funda probablemente en una interpretación (o un desarrollo semántico) del nom-

2. Cf. Mt 3,2; 4,17; 10,17; Mc 1,15; Lc 10,9.11. Sin embargo, debemos mencionar la inclusión significativa entre Ap 1,3 y 22,10 sobre la proximidad del tiempo: "el tiempo está cerca". Cf. E. COTHENET, "La venue ou les venues du Christ dans l'Apocalypse", Exégèse et liturgie, LeDiv 175, Cerf - Paris - 1999, II, 207. bre de Dios (YHWH) en Ex 3,14. ${ }^{3}$ De hecho, sabemos que la respuesta misteriosa de Dios ('ehyeh ", ${ }^{\text {šer }}$ 'ehyeh) a Moisés que le pide su nombre, puede ser comprendida de varias maneras: "Yo soy el que soy" o "Yo seré quien seré", entre otras. Interpretaciones judaicas posteriores entendieron esta expresión como una afirmación de la eternidad divina. Es el caso de Filón de Alejandría (Mos. 1,75) y de la traducción de los Setenta. Pero el Tárgum palestino del Seudo-Jonatán la interpretó de manera diferente, desarrollando la significación de la expresión en tres términos, que expresan la existencia pasada, presente y futura: "Yo soy aquel que era y aquel que seré" (Ex 3,14), o "Yo soy aquel que soy, que era, y soy aquel que seré" (Dt 32,29). Pero la expresión que encontramos en el Apocalipsis tiene un trazo original: el tercer miembro no es el futuro del verbo "ser" sino el participio presente del verbo "venir" ("aquel que viene"4). Juan escogió el verbo "venir" en lugar del verbo "ser" sin duda para significar la venida de Dios para el juicio, tema que ya está muy presente en el Antiguo Testamento. ${ }^{5}$ Es significativo que encontremos en 11,17 y 16,5 la expresión abreviada "Aquel que es y que era". La ausencia del tercer miembro se explica por el hecho de que el juicio de Dios vino y, por consiguiente, no se debe seguir esperándolo: “Te damos gracias, Señor Dios Todopoderoso, Aquel que es y que era, porque has asumido tu inmenso poder para establecer tu reinado". 6

Indiquemos también que el Espíritu Santo, sea a través de la expresión "los siete espíritus que están delante de su trono", sea a través de la expresión simple "el Espíritu", nunca es sujeto del verbo "venir" en el Apocalipsis, contrariamente al Padre y a Cristo. Es un punto interesante que merecería ser profundizado para la neumatología del Apocalipsis. ${ }^{7}$

3. Nos apoyamos aquí sobre R. BAUCKHAM, The Theology of the Book of Revelation, New Testament Theology, Cambridge University Press - Cambridge - 1993, 28-29, donde el autor examina en detalle esta expresión. Su punto de vista es el de muchos comentaristas.

4. Literalmente en griego: "el viniente".

5. Cf. SI 96,13; 98,9; Is 40,10; 66,15; Za 14,5.

6. Es probablemente por error que algunos manuscritos griegos mencionan aquí el tercer miembro, quizás por armonización con 1,4.8 y 4,8

7. Sobre la neumatología del Apocalipsis en general, ver BAUCKHAM, Theology, capítulo 5: "The Spirit of Prophecy"; F. Contreras Molina, El Espíritu en el libro del Apocalipsis, Koinonia 28, Secretariado Trinitario - Salamanca - 1987. 


\section{Las tres afirmaciones "vengo" de Cristo en las cartas a las Iglesias}

Podemos ahora concentrarnos sobre las ocurrencias del verbo "venir" que tienen una connotación cristológica. En primer lugar, debemos considerar las siete afirmaciones "vengo" de Cristo, empezando por las tres afirmaciones que están en las cartas a las Iglesias de Asia. Antes de examinarlas en detalle, hagamos tres observaciones generales a su respecto:

La primera concierne su distribución a través del libro. Tres de estas afirmaciones se encuentran en las cartas a las Iglesias de Asia (2,5.17; $3,11)$, tres al final del libro $(22,7.12 .20)$ y solamente una en la sección intermedia del libro (Ap 4-20), en Ap 16,15. Si tenemos en cuenta que 1,7 afirma que Cristo viene luego, no podemos dejar de ver que la afirmación de la venida de Cristo realiza como una gran inclusión de todo el contenido del Apocalipsis. Todo lo que se dice dentro de esta inclusión debe ser visto bajo esta luz.

Observemos también que cinco veces, en particular (y esto es significativo) en las tres últimas ocurrencias del verbo érjomai en la boca de Cristo, su venida es afirmada de manera cualificada con el adverbio "pronto" (tajý): 2,16; 3,11; 22,12.20. Debemos esclarecer el sentido de este adverbio.

En fin, en las siete ocurrencias, el verbo érjomai está en presente y nunca en futuro. Eso no debe ser casualidad y supone probablemente una intención teológica que conviene esclarecer.

Estudiemos ahora las tres ocurrencias del verbo "venir" en la boca de Cristo en las cartas.

La primera se encuentra en la carta a la Iglesia de Éfeso: "Date cuenta, pues, de dónde has caído; arrepiéntete y vuelve a tus primeras obras. Si no, vengo a ti (érjomaí soi) y cambiaré de su lugar tu candelero, si no te arrepientes" $(2,5)$. La venida de Cristo es afirmada aquí de manera condicional, como una amenaza para la Iglesia de Éfeso, en caso de que ella rechace el arrepentimiento. ${ }^{8}$

8. ¿En qué consiste exactamente la falta de esta Iglesia? En que ella perdió su primer amor. Muy probablemente, debemos comprender que ella perdió el fervor de su amor, tal vez por ser un amor de neófito, ya que el Apocalipsis fue escrito cincuenta años (más o menos) después de la primera evangelización de Éfeso. Sin embargo, la ra-
Podemos decir lo mismo con respecto a la segunda ocurrencia que se encuentra en la carta a la Iglesia de Pérgamo: "Arrepiéntete, pues; si no, vengo pronto a ti (érjomaí soi tajý) y lucharé contra ésos con la espada de mi boca" $(2,16)$. Cristo amenaza con venir a golpear a los Nicolaítas, de los cuales debemos confesar que sabemos muy poco. La interpretación más verosímil, según nuestro parecer (entre otras razones, porque es la más sencilla), es que se trataba de miembros de la comunidad cristiana de Pérgamo que incitaban a comer carne inmolada a los ídolos, no por las enseñanzas de Pablo (más o menos correctamente comprendido), sino por una preocupación exagerada de adaptación a la sociedad pagana, imitando a la gente para no causar problemas. ${ }^{9}$

La tercera ocurrencia se encuentra en la carta a la Iglesia de Filadelfia: "Vengo pronto (érjomai tajý); mantén con firmeza lo que tienes, para que nadie te arrebate tu corona" $(3,11)$. Aquí, la Iglesia de Filadelfia no recibe ninguna crítica y la venida de Cristo es afirmada de manera incondicional.

Debemos también señalar la carta a Tiatira, en la que Cristo declara a los que no siguieron la doctrina de Jezabel: "pero lo que tenéis, retenedlo hasta que yo venga (hếx $\overline{\boldsymbol{o}})$ " $(2,25)$. Cierto, no encontramos aquí el verbo érjomai sino el verbo hếk̄ que, sin embargo, está muy próximo al sentido. Aquí también la venida de Cristo es afirmada de manera incondicional.

Otro texto que utiliza el verbo hếk $\overline{\boldsymbol{o}}$ se encuentra en la carta a Sardes: "Acuérdate, por tanto, de cómo recibiste y oíste [la palabra]: guárda[la] y arrepiéntete. Porque si no estás en vela, vendré (hếxō) como un ladrón, y no sabrás a qué hora vendré sobre ti” $(3,3)$. Aquí, otra vez, se trata de una venida condicional: Cristo amenaza con venir a sorprender a la Iglesia de Sardes si ella no despierta de su sueño espiritual profundo.

zón por la que ella perdió el fervor no es clara. Es posible que esta Iglesia haya caído en una lógica de eficiencia, olvidando que el trabajo no sustituye al amor. Otros comentaristas piensan que la Iglesia de Éfeso se endureció en la lucha que debió sostener contra los falsos apóstoles y contra los Nicolaítas; esta interpretación también es posible.

9. Las informaciones que encontramos con respecto a ellos en los Padres de la Iglesia, o dependen del Apocalipsis, o son dudosas en el plano de la crítica histórica (cf. IRENeO DE Lyon, Contra las herejías, I, 26, 3; Clemente de Alejandría, Stromates, II, 118, 3-5; III, 25-26). Hicimos un estudio detallado de la cuestión de los Nicolaítas en Le septénaire des lettres de l'Apocalypse de Jean, Université Marc Bloch - Strasbourg - 2005, 303317 
Entonces, hay cinco cartas (Éfeso, Pérgamo, Tiatira, Sardes, Filadelfia) que evocan la venida de Cristo. En tres casos, esta venida es condicional (si las Iglesias implicadas no se arrepienten), en los otros dos casos, se trata de la venida escatológica de Cristo. Esto nos conduce necesariamente a distinguir entre dos venidas de Cristo en su Iglesia: por una parte, hay una venida condicional para el juicio de las Iglesias culpables, y por otra parte hay una venida incondicional que solamente puede ser la venida escatológica. Consideremos la primera venida más detalladamente. En la visión inaugural de Ap 1, Juan describe a Cristo que se le aparece con trazos judiciales. De hecho, Cristo tiene una espada aguda que sale de su boca; tiene el jus gladii que es una autoridad judicial. La metáfora de los ojos "como llama de fuego" $(1,14 \mathrm{~b})$ podría también tener una dimensión judicial. De hecho, por una parte, ella expresa el carácter penetrante de la mirada de Cristo. Por otra parte, el motivo del fuego es frecuentemente ligado al tema del juicio en la Escritura. ${ }^{10}$ Cristo tiene también las llaves de la muerte y del Hades, lo cual es otro simbolismo judicial: Cristo es como un juez que tiene el poder de mandar a la cárcel y de hacer salir de ella como quiere. Entonces, es como juez que Cristo se aparece a Juan en la visión inaugural. ${ }^{11}$

\section{La venida anticipada del juez de las Iglesias}

Varios estudios se dedicaron al género literario de las cartas a las siete Iglesias de Asia. Entre los más importantes, están los de Müller y Aune, que mostraron la presencia en el septenario de las cartas de formas literarias de oráculos de juicio. ${ }^{12}$ Para Aune, en particular, si el género literario de las cartas es el del decreto real o imperial, especialmente con la

10. Ver por ejemplo Mt 3,12; 13,$30 ; 25,41$

11. Aunque debamos reconocer que el sustantivo krísis y el verbo krínō están ausentes de los capítulos 1-3 del Apocalipsis. Si bien el vocabulario explícito del juicio está ausente, los símbolos del juicio sí están presentes. Por eso, no parece justificado excluir de las cartas a las Iglesias la perspectiva del juicio, como lo hace J. F. TORIBIO CUADRADO en "El Viniente". Estudio exegético y teológico del verbo EPXE $\Sigma \Theta A I$ en la literatura joánica, Monografías de la Revista "Mayéutica" 1, Marcilla - 1993, 138.

12. Cf. U. Mülter, Prophetie und Predigt im Neuen Testament. Formgeschichtliche Untersuchungen zur urchristlichen Prophetie (StNT 10, Gütersloher Verlagshaus Gerd Mohn - Gütersloh - 1975) ; D. E. AUNE, "The Form and Function of the Proclamations to the Seven Churches (Revelation 2-3)", NTS 36 (1990), 182-204. forma “así habla..." (Táde légei), su modo es el de oráculos parenéticos de juicio y salvación.

La fórmula "sé" (ô̂da) introduce la descripción hecha por Cristo de la situación de la comunidad. Las obras buenas son mencionadas con aprobación y las faltas son criticadas con vigor. El final de cada carta incluye una promesa de salvación o una amenaza de condenación. Estamos realmente, entonces, en presencia de un juicio a las Iglesias de Asia por parte de Cristo; un juicio de "aquel que sondea los riñones y los corazones" $(2,23)$.

No podemos estudiar aquí en detalle el juicio en las cartas. Sin embargo, queremos hacer una observación: este juicio es un juicio anticipado en relación con el juicio final (Ap 20,11-15). De hecho, no se trata de un juicio que acontece al final de la historia, como, por ejemplo, el juicio final de Mt 25,31-46. Antes de la venida gloriosa de Cristo, las Iglesias de Asia reciben este juicio de Cristo por intermedio de Juan. Ya vimos que las promesas de Cristo a las Iglesias fieles son condicionales: "Mantente fiel hasta la muerte y te daré la corona de la vida" $(2,10 b)$. De manera semejante, los castigos para las Iglesias infieles son también condicionales: "Date cuenta, pues, de dónde has caído, arrepiéntete y vuelve a tus primeras obras. Si no, vengo a ti y cambiaré de su lugar tu candelero, si no te arrepientes" (2,5); "Si no estás en vela, vendré como ladrón" (3,3). El carácter condicional de las promesas y de los castigos confirma que todavía no estamos en el término de la historia: hay tiempo para perseverar en la fidelidad o para arrepentirse de sus culpas; lo cual, evidentemente, ya no sucede en el juicio final de Ap 20,11-15 y en Mt $25 .{ }^{13}$ Además, la carta a la Iglesia de Laodicea muestra claramente que Cristo no se limita a juzgar a esta Iglesia sino que le ofrece los remedios para su recuperación espiritual $(3,18)$.

Observemos que la existencia de un juicio anticipado a la Iglesia es también afirmada por Pablo en su primera carta a los Corintios y por la primera carta de Pedro:

Si nos juzgáramos a nosotros mismos, no seríamos castigados. Mas, al ser castigados, somos corregidos por el Señor, para que no seamos condenados con el mundo. (1 Cor 11,31-32)

Porque ha llegado el tiempo de comenzar el juicio por la casa de Dios. (1 Pe $4,17)$

13. Cf. Toribio Cuadrado, "El Viniente", 132. 
En 1 Cor 11 el juicio anticipado a la Iglesia es un juicio de corrección, como es el caso en Ap 3,19: "Yo reprendo y castigo a todos los que amo". De hecho, lo que Pablo dice de aquellos que reciben indignamente el cuerpo de Cristo, tiene semejanzas con el juicio severo de Cristo sobre la Jezabel de Tiatira.

Pues quien come y bebe sin discernir el Cuerpo, come y bebe su propia condena. Por eso hay entre ustedes muchos enfermos y muchos achacosos, y mueren no pocos. (1 Cor 11,29-30)

Mira, a ella voy a arrojarla al lecho del dolor, y a los que adulteran con ella, a una gran tribulación, si no se arrepienten de sus obras. $Y$ a sus hijos, los voy a herir de muerte. (Ap 2,22-23)

En ambos casos, de hecho, se trata de un castigo divino cuya finalidad es medicinal: la conversión de los cristianos. Como lo dice Comblin:

En las siete cartas a las iglesias, el anuncio de la venida del Hijo del Hombre significa a veces esta intervención anticipada del juez final que no tiene como finalidad determinar la suerte de los cristianos, sino salvarlos y prepararlos para el juicio, hacer su educación. ${ }^{14}$

¿Cuáles son las críticas de Cristo a las Iglesias infieles (en diversos grados)? Estas comprenden los puntos siguientes:

- $\quad$ Éfeso perdió su primer amor y no es más una Iglesia fervorosa.

- Pérgamo tolera a los Nicolaítas que incitan a un compromiso con las prácticas del ambiente pagano.

- $\quad$ Tiatira tolera a Jezabel que difunde en ella la doctrina de sus falsas profecías, seduciendo así a numerosos fieles de la comunidad.

- $\quad$ Sardes es una Iglesia que duerme y no está ya en vela.

- Laodicea es una Iglesia satisfecha de sí misma y que, por esta razón, cayó en una tibieza detestable.

Solamente dos Iglesias (Esmirna y Filadelfia) no reciben críticas. Cristo las exhorta a la firmeza y a la fidelidad, anunciándoles la venida de pruebas de las que deben salir victoriosas.

Observemos también que Cristo declara a Laodicea que él ya está a la puerta y llama con el deseo de entrar $(3,20)$ :

Mira que estoy (idoù héstêk $\boldsymbol{k}$ ) a la puerta y llamo; si alguno oye mi voz y me abre la puerta, entraré en su casa y cenaré con él y él conmigo.

14. J. Combuin, Le Christ dans l'Apocalypse, Desclée - Paris - 1965, 61
El perfecto (héstēka) indica la continuación en la duración: Cristo espera que uno quiera abrirle la puerta. El contraste con el verbo "venir" es interesante: Cristo entrará en la casa del fiel de Laodicea solamente si le abre la puerta. La fórmula de escucha "El que tenga oídos, oiga lo que el Espíritu dice a las Iglesias", repetida al final de cada carta, repercute las amenazas y las exhortaciones de cada carta a las otras Iglesias.

El Apocalipsis presenta entonces esta paradoja significativa: Cristo ya está presente (está a la puerta), anuncia su venida próxima (la venida escatológica incondicional) y amenaza a las Iglesias culpables con una venida intermedia y correccional, antes de su venida última. Encontramos entonces en este libro una tensión entre una presencia (actual pero escondida) y unas venidas (intermedia y después final). La venida de Cristo no será la de un ser distante sino la de una persona ya presente de manera escondida en medio de las Iglesias, ya que camina en medio de los siete candeleros de oro $(2,1)$.

Volvamos sobre una observación hecha arriba: todas las ocurrencias del verbo venir en las cartas a las Iglesias están en presente: "vengo" (érjomai), incluso cuando se trata de las venidas condicionales. ¿Cómo entender el presente? Podemos decir, claro, que este presente tiene valor de futuro y así es traducido habitualmente. Sin duda; pero ¿acaso no hay nada más? Evocando su venida futura en el presente, Cristo parece tener la intención de mostrar la proximidad y la rapidez de su venida. Su vuelta está tan próxima que ya aparece como presente.

\section{La venida de Cristo en Ap 16,15}

\section{El problema del lugar del versículo 16,15}

Después de las ocurrencias del verbo "venir" en las cartas, veamos la ocurrencia en el versículo 16,15. Este versículo plantea un problema particular, porque, a primera vista, parece ser una interpolación. Citemos este versículo en su contexto, que es el de la sexta copa: ${ }^{15}$

15. Con Nestle-Aland27, adoptamos la versión con la primera persona del singular ("Mira que vengo como ladrón...") de preferencia a la variante con la tercera persona del singular, muy aislada en la tradición manuscrita. 
12 El sexto derramó su copa sobre el gran río Éufrates; y sus aguas se secaron para preparar el camino a los reyes del Oriente. ${ }^{13}$ Y vi que de la boca del Dragón, de la boca de la Bestia y de la boca del falso profeta, salían tres espíritus inmundos como ranas. ${ }^{14}$ Son espíritus de demonios que realizan signos y van donde los reyes de todo el mundo para convocarlos a la gran batalla del gran Día del Dios Todopoderoso. 15 Mira que vengo como ladrón. Dichoso el que esté en vela y conserve sus vestidos, para no andar desnudo y que se vean sus vergüenzas. ${ }^{16}$ Los convocaron en el lugar llamado en hebreo Harmaguedón.

A primera vista, podemos tener la impresión de que el versículo 15 viene a interrumpir inútilmente el hilo de la narración, y concluir que se trata de una interpolación. Es la opinión de numerosos exegetas. Para Charles, por ejemplo, este versículo no tiene nada que hacer en este lugar; debía estar originalmente entre 3,3a y 3,3b, o debería ser colocado antes de 3,18.16 Sin embargo, esta hipótesis no encuentra ningún apoyo en la tradición manuscrita. Aune también considera este versículo como una interpolación que pertenece a una segunda edición del Apocalipsis. ${ }^{17}$ Prigent reconoce que, si el versículo 15 fuera suprimido, el versículo 16 seguiría muy naturalmente al versículo 14 . Por otra parte, si hubo una adición, ella no puede venir sino del autor del Apocalipsis, porque las ideas y las imágenes que encontramos en el versículo 15 tienen paralelos muy claros en 3,3 y $3,18.18$

Si bien una gran mayoría de comentaristas concluye que es una interpolación, algunos, sin embargo, tienen un parecer diferente. Es el caso de Caird, que piensa que antes de utilizar la "cirugía", debemos tratar de elaborar una teoría que explique el lugar actual del versículo 16,15. En primer lugar, no es la primera vez que la voz de Cristo es oída en las visiones de Juan con una bendición que, al mismo tiempo, es una llamada a la lealtad (cf. 14,13). En el discurso escatológico de Jerusalén de Mc 13, Jesús había dicho a sus discípulos que los últimos días de Jerusalén vendrían con una rapidez que no permitiría ningún aplazamiento: el hombre que está haciendo la siesta en la azotea debe huir hacia las montañas sin

16. R. H. ChARLES, A Critical and Exegetical Commentary on the Revelation of St. John, 2 vol., International Critical Commentary, Edinburgh - 1920, II, 49.

17. D. E. Aune, Revelation, Word Biblical Commentary 52, Word Books Publisher Dallas - 1997-1998, II, 896.

18. P. Prigent, L'Apocalypse de saint Jean, Commentaire du Nouveau Testament deuxième série XIV, Labor et Fides - Genève - 2000³, 365-366. siquiera volver al interior de su casa para tomar sus cosas, y el hombre que está trabajando en el campo debe escapar sin volver a su casa para tomar su manto (Mc 13,15-16). Con palabras semejantes, el Cristo celeste advierte a aquellos que lo siguen que deben estar prontos para los últimos días de Babilonia. Con certeza, se trata de una preparación espiritual, como la que se le pide a Sardes y a Laodicea $(3,2.18)$. De hecho, para Caird:

El peligro no es que los cristianos sean tomados por sorpresa por la invasión que viene del este, sino que no sean capaces de reconocer en ella la venida del Señor. Aquí, como en las cartas $(2,5.16 ; 3,3)$, Juan reinterpreta la creencia tradicional en la venida de Cristo, animando a sus amigos a buscarlo en las crisis de la historia. Él viene como un ladrón y toma los hombres por sorpresa, porque la hora y el modo de su venida están ocultos a sus ojos. ${ }^{19}$

En conclusión, Caird considera plenamente conveniente el lugar actual del versículo 16,15 .

Hemer ofrece otros argumentos para mantener el versículo en su lugar actual. No existe ningún testimonio en la tradición manuscrita de que el versículo estuviera situado en otro lugar en el pasado (entre 3,3a y 3,3b, por ejemplo), y no se ve por qué este versículo habría sido interpolado en un lugar donde parece inconveniente. Hemer sugiere ante todo que el contexto de 16,15 tiene en vista las circunstancias de Sardes:

Aquí, el movimiento ciego de las fuerzas terrestres hacia un clímax no visto suscita un grito final de advertencia en las palabras de Jesús. Aquí se realizan los acontecimientos escatológicos contra los cuales la Iglesia de Sardes era advertida de quedarse en vela. Las imágenes sugieren un último grito dirigido a los cristianos de esta ciudad. 20

En un estudio consagrado a la composición del Apocalipsis, Bauckham compara el papel de Ap 16,15 en el septenario de las copas, al papel de las intercalaciones (Ap 7 y Ap 10-11,1-14 respectivamente) en los septenarios de los sellos y de las trompetas. En la tercera serie de juicios, el de las copas, no hay intercalación. El versículo 16,15 tiene un papel comparable, en cierto sentido, al de las intercalaciones en los dos primeros

19. G. B. CAIRD, The Revelation of St. John the Divine, Black's New Testament Commentaries, A \& C Black Publishers - London - 1966, 209.

20. C. J. HeMER, The Letters of the Seven Churches of Asia in their Local Setting, JSNTSS 11, JSOT Press - Sheffield - 1986, 146. 
septenarios, pero no indica un plazo, al contrario: enfatiza el carácter repentino de la venida final del Señor para el juicio:

Esta serie [de las copas] progresa con rapidez y sin impedimentos hacia el séptimo juicio que es el juicio final (...). El tiempo del arrepentimiento ya pasó (cf. 10,6-7).21

Para concluir este punto, digamos que la interpolación del versículo 15 no se impone en absoluto. Los argumentos a su favor no tienen apoyo en la tradición manuscrita y, sobre todo, parecen proceder de un raciocinio lógico poco apropiado para el lenguaje simbólico del Apocalipsis. Este versículo puede muy bien ser comprendido en su lugar presente. Entonces, podemos considerarlo como situado aquí intencionalmente por Juan para exhortar a las Iglesias, particularmente a las de Sardes y Laodicea.

\section{Una última exhortación a Sardes y a Laodicea}

Observemos con Caird y Hemer que 16,15 parece ser una advertencia recordando las cartas a Sardes y a Laodicea. De hecho, este versículo une trazos que no se encuentran sino en las cartas a Sardes (la venida de Cristo como ladrón) y a Laodicea (el motivo de la desnudez). De este modo, estas dos Iglesias reciben como una última exhortación de Cristo en este momento crucial de la historia que es la sexta copa. ¿Por qué estas dos Iglesias y no otras? Probablemente porque ellas son las dos Iglesias en el estado espiritual peor, las que recibieron más reproches de Cristo en las cartas. Sardes es una Iglesia sumergida en el sueño y que no está más en vela; la venida de Cristo sólo puede sorprenderla como la venida de un ladrón. Laodicea está llena de sí misma, actitud que no favorece en absoluto estar en vela. Apareciendo de manera repentina e inesperada en medio de la narración de la sexta copa, en la primera persona del singular y buscando un efecto de sorpresa, el versículo 16,15 recuerda la exigencia de estar pronto para la venida gloriosa de Cristo y sugiere el peligro, para aquel que olvidara esta exigencia, de ser llevado por los flagelos descritos por las copas. Esta advertencia, que vale naturalmente para todas las Iglesias, vale de modo particular para las dos Iglesias en peor estado a nivel espiritual: Sardes y Laodicea.

21. R. BAUCKHAm, "Structure and Composition", The Climax of Prophecy. Studies on the Book of Revelation, T\&T Clark - Edinburgh - 1993, 14.

\section{4. "¡Ven!"}

Veamos ahora las siete ocurrencias en imperativo: “iven!" $(6,1.3 .5 .7 ; 22,17(2) \cdot 20)$.

\section{La apertura de los cuatro primeros sellos}

Las cuatro ocurrencias al inicio del capítulo 6 están situadas en la apertura de los cuatro primeros sellos:

Y seguí viendo. Cuando el Cordero abrió el primero de los siete sellos, oí al primero de los cuatro Vivientes que decía con voz de trueno: "Ven". (v. 1) Cuando abrió el segundo sello, oí al segundo Viviente que decía: "Ven". (v. 3) Cuando abrió el tercer sello, oí al tercer Viviente que decía: "Ven". (v. 5a) Cuando abrió el cuarto sello, oí la voz del cuarto Viviente que decía: "Ven". (v. 7)

¿A quién se dirige el grito "ven" lanzado por un Viviente cuando se abren los sellos? Hay solamente dos posibilidades: a Juan, o al jinete. En la primera hipótesis, Juan sería llamado a acercarse para ver mejor lo que va a acontecer. Vemos algo semejante en otros lugares del Apocalipsis:

Entonces vino uno de los siete ángeles que llevaban las siete copas y me habló: "Ven (deûro), que te voy a mostrar el juicio de la célebre Prostituta, que se sienta sobre grandes aguas". $(17,1)$

Entonces vino uno de los siete ángeles que tenían las siete copas llenas de las siete últimas plagas, y me habló diciendo: "Ven (deûro), que te voy a enseñar a la Novia, a la Esposa del Cordero". $(21,9)^{22}$

Así, a primera vista, podría suceder lo mismo en la apertura de los sellos. Sin embargo, dos argumentos nos conducen en sentido contrario. Primero, está el adverbio deûro en lugar del verbo érjomai. Segundo, en 17,1 y en 21,9, el ángel invita a Juan a venir diciéndole explícitamente que quiere mostrarle algo, lo que no sucede en la apertura de los sellos. Es probable, entonces, que la invitación a venir, gritada por los Vivientes, se dirija a los jinetes sucesivos. ¿Qué representan estos jinetes? Representan probablemente el juicio de Dios bajo la forma de tres flagelos tradicionales en el Antiguo Testamento: la guerra, el hambre y la peste, como se puede ver en varios textos de Ezequiel, como este:

22. Aquí no tomamos en cuenta 19,17 que invita a las aves volando en el zenit a venir al gran banquete de Dios. 
Lanzaré contra ellos las terribles flechas exterminadoras del hambre, que yo enviaré para exterminarlos; acrecentaré entre ustedes el hambre y destruiré sus provisiones de pan. Enviaré contra ustedes hambre y bestias feroces, que te dejarán sin hijos, la peste y la sangre pasarán por ti, y haré venir contra ti la espada. Yo, Yahvé, he hablado. (Ez 5,16-17) $)^{23}$

André Feuillet muestra de manera convincente que el jinete blanco no es un flagelo, porque ninguno de sus trazos es negativo. El color blanco alude al cielo en todas las otras partes del Apocalipsis. En el Nuevo Testamento, la corona es símbolo de victoria sobre el mal. ${ }^{24}$ Según Feuillet, el primer jinete sería una personificación del juicio divino y los otros tres flagelos serían mandados por Dios para golpear a los pecadores. ${ }^{25}$ Feuillet no cree posible identificar al jinete del primer sello con el jinete blanco de Ap 19, explícitamente designado como el Verbo de Dios, pero los argumentos contra esta identificación están lejos de ser decisivos. En particular, el hecho de que el Cordero que abre los sellos sea Cristo (todos están de acuerdo sobre eso) no significa que el jinete blanco no pueda ser también Cristo. De hecho, cada símbolo conduce no a un personaje distinto, sino a una función distinta. Pensamos que el jinete blanco del primer sello es Cristo, por una parte en razón de los argumentos de Feuillet mostrando que no tiene ningún trazo negativo; por otra parte porque, según un buen principio metodológico, debemos interpretar el Apocalipsis ante todo por sí mismo. Ahora bien, el único otro texto donde aparece un jinete blanco es el capítulo 19 con la visión de Cristo como Verbo de Dios. Está también la expresión enfática de 6,2: "salió como vencedor y para seguir venciendo (exêlthen nikôn kaì hína nikếsēe)", que hace pensar en 5,5: "ha vencido el león de la tribu de Judá, el retoño de David". Por fin, observemos un punto curioso: la conjunción de la corona y del arco. Esta conjunción aparece en un único otro texto, en Sal 21,4.13.

Te adelantaste con buenos augurios, / coronaste su cabeza de oro fino. (v. 4) Que tú les harás retroceder, / asestando tu arco contra ellos. (v. 13)

Ahora, el salmo 21 es un salmo mesiánico y el rey del que se trata aquí es el Mesías. En total, tenemos entonces una convergencia de indi-

23. Ver también, por ejemplo: Ez 6,11-12; 7,15; 12,16; Jr 14,12; 21,7-9; 24,10.

24. Cf. 1 Ts 2,19; 1 Cor 9,25; Flp 4,1; 2 Tm 4,8; Sant 1,12. Ap 9,7 parece ir en el sentido inverso, pero el texto dice que las langostas tienen "como coronas" (hōs stéfanoi).

25. Cf. A. Feuillet, "Le premier cavalier de l'Apocalypse", ZNW 57 (1966), 229-259. cios que favorecen una interpretación cristológica del jinete blanco. ${ }^{26}$ Este aparece como el ejecutor del juicio de Dios, lanzando sus "flechas" bajo la forma de los tres flagelos de la guerra, el hambre y la peste. Cierto, contrariamente al capítulo 19, la identidad del jinete blanco del capítulo 6 no es evidente, pero hay probablemente una razón teológica para esto: antes de la hora de la parusía, la presencia de Cristo en el mundo queda escondida, al contrario del regreso último de Cristo al final de los tiempos, que será manifiesto.

Si nuestra interpretación es correcta, el primer Viviente se dirige a Cristo en la apertura del primer sello. Cristo es llamado a venir para ejercer el juicio sobre los hombres pecadores, aquellos que el Apocalipsis llama "los habitantes de la tierra". Este juicio se ejerce por medio de tres flagelos tradicionales, pero se orienta claramente a la conversión de los pecadores y no a su destrucción, como vemos en 9,20-21:

Pero los demás hombres, los no exterminados por estas plagas [de las trompetas], no se convirtieron de las obras de sus manos; no dejaron de adorar a los demonios y a los ídolos de oro, de plata, de bronce, de piedra y de madera, que no pueden ver ni oír ni caminar. No se convirtieron de sus asesinatos ni de sus hechicerías ni de sus fornicaciones ni de sus rapiñas.

Esta venida del juicio es deseada por los mártires cristianos que se expresan en el quinto sello (es la única vez que hablan en el libro):

Se pusieron a gritar con fuerte voz: “ ¿Hasta cuándo, Dueño santo y veraz, vas a estar sin juzgar y sin hacer justicia (kríneis kai ekdikeîs) por nuestra sangre respecto de los habitantes de la tierra?"27

\section{La llamada del Espíritu y de la Iglesia}

Las otras tres ocurrencias del verbo "venir" en imperativo se encuentran al final del libro, en el capítulo 22:

Y el Espíritu y la Esposa dicen: "Ven". Y el que oye, diga: "Ven". $(22,17)$

Dice el que da testimonio de todo esto: "Sí, vengo pronto". ¡Amén! ¡Ven, Señor Jesús! $(22,20)$

26. La interpretación cristológica del primer caballero es común entre los comentaristas medievales.

27. Ap 6,10. Debemos notar que el verbo $\boldsymbol{e} \boldsymbol{k} \boldsymbol{d} \boldsymbol{i} \boldsymbol{k} \boldsymbol{e} \boldsymbol{\boldsymbol { o }}$, que significa "hacer justicia", no tiene siempre el sentido de "tomar venganza", como vemos en Lc 18,3. 
El versículo 22,17 se encuentra a continuación de dos afirmaciones de Cristo diciendo que él viene pronto (22,7.12). Aparece entonces como la respuesta suscitada por el Espíritu Santo en el corazón de la Iglesia. La venida de Cristo es cierta, pero los cristianos no deben esperarla con miedo, como los habitantes de la tierra que temen mucho la venida del día de la cólera de Dios y del Cordero (6,15-17). Deben, más bien, aguardarla con esperanza. El Espíritu los ayuda, poniendo en su corazón la invocación que pide la venida de Cristo. El versículo 22,20, penúltimo del libro, repite esta invocación.

Al final de este estudio de las ocurrencias del verbo "venir" en el Apocalipsis, tenemos por una parte la venida anticipada de Cristo para juzgar a su Iglesia (simbolizada por las siete iglesias de Asia); este juicio busca la conversión de las iglesias. Por otra parte, tenemos la venida de Cristo al mundo para ejercer el juicio sobre los pecadores; allí también, el juicio está orientado a la conversión.

\section{5. ¿Otras venidas de Cristo?}

Resultaba normal empezar nuestro estudio por los textos ligados al verbo "venir". Debemos ahora ampliar nuestra búsqueda a otros pasajes que parecen tener una relación con la venida de Cristo, aunque no utilicen este verbo.

\section{La visión inaugural}

Después de la introducción general del libro (1,1-8), el Apocalipsis empieza con la visión inaugural de Cristo por Juan el día del Señor (1,920). Hemos visto que las cartas a las iglesias de Asia, que siguen a continuación, mencionan dos venidas de Cristo, pero podemos preguntarnos respecto de la visión misma: ¿acaso estamos en presencia de una venida de Cristo? En realidad, Juan no dice que ve a Cristo viniendo hacia él; Cristo se le aparece presente en medio de las Iglesias. El inicio de la carta a Éfeso lo presenta como "aquel que camina entre los siete candeleros de oro" $(2,1)$, o sea, entre las iglesias. Entonces, Cristo aparece como aquel que está presente en su Iglesia, como aquel que la acompaña en su camino, pero la visión misma no evoca una venida. Parece inadecuado, entonces, hablar de una "venida litúrgica" de Cristo como lo hace Cothe- net. ${ }^{28}$ Sería mejor hablar de la presencia de Cristo en su Iglesia, en particular durante la liturgia, ya que la visión de Juan acontece el día del Señor (o sea, un domingo).

\section{La siega y la vendimia}

Y seguí viendo. Había una nube blanca, y sobre la nube sentado uno como Hijo de hombre, que llevaba en la cabeza una corona de oro y en la mano una hoz afilada. $(14,14)$

Este hijo de hombre sentado sobre una nube blanca (una reminiscencia de Dn 7,13), sólo puede ser Cristo, particularmente por razón del vínculo con 1,7. Invitado por un ángel, él mete su hoz y siega la mies de la tierra. A primera vista, algunas semejanzas con la gran escena del juicio final de Mt 25 harían pensar que se trata de una venida para el juicio:

Cuando el Hijo del hombre venga en su gloria acompañado de todos sus ángeles, entonces se sentará en su trono de gloria. (Mt 25,31)

Sin embargo, el sentido de la escena de Ap 14 es diferente al del juicio final de Mt 25. La siega de Ap 14 alude probablemente a las naciones convertidas a Cristo, cuyas primicias son los 144.000 mencionados poco antes en el mismo capítulo (cf. 14,4). Cristo acoge a las naciones para integrarlas a la Iglesia; pero aquí también, la escena no evoca una venida. Parece discutible interpretar tanto esta escena como la de la vendimia como un juicio. De hecho, el juicio acontecerá más tarde en el capítulo 20. Aquí, se trata más bien de una ilustración simbólica de la fecundidad maravillosa (la siega) del sacrificio de los mártires cristianos cuya sangre sobreabunda de manera impresionante (la vendimia). ${ }^{29}$

\section{El jinete blanco de Ap 19}

El tercer texto que debemos estudiar es Ap 19,11-21 donde Juan ve a Cristo, el jinete blanco acompañado por los ejércitos celestes, golpeando con su espada a los reyes de la tierra reunidos contra él, y entregando sus cadáveres a las aves del cielo:

28. Cothenet, "Venue", 213

29. Sobre estas dos escenas, ver el estudio excelente de A. FeuIlLet: "La moisson et la vendange de l'Apocalypse (14,14-20)", NRTh 94 (1972) II, 113-132; III, 225-250. 
Entonces vi el cielo abierto, y había un caballo blanco: el que lo monta se llama "Fiel" y "Veraz"; y juzga y combate con justicia. $($ Ap 19,11)

Aquí otra vez, el vocabulario de la venida está ausente. Sin embargo, la situación cambia si tenemos en cuenta las imágenes. De hecho, Cristo monta un caballo y es seguido por los ejércitos celestes $(19,14)$, lo que implica un cambio de lugar, una venida para los reyes de la tierra. Además, la escena tiene claramente el carácter de un combate escatológico entre Cristo y sus enemigos conducidos por la Bestia de la tierra. También, es inmediatamente seguida por el juicio final del capítulo 20. Parece, entonces, que se trata de la venida escatológica de Cristo en la parusía. El carácter guerrero de la descripción no debe engañarnos. Por una parte, debemos recordar que el combate cristiano no es material sino espiritual, como lo dice san Pablo: ${ }^{30}$

Revístanse de las armas de Dios para poder resistir a la acechanzas del diablo Porque nuestra lucha no es contra la carne y la sangre, sino contra los principados, contra las potestades, contra los dominadores de este mundo tenebroso, contra los espíritus del mal que están en el aire. (Ef 6,11-12)

Por otro lado, debemos tener en cuenta el lenguaje simbólico del Apocalipsis, lo que es olvidado muy a menudo. Con estos dos principios, podemos buscar una interpretación más satisfactoria que la de una simple masacre sin merced, exigida por la justicia divina y que, en último término, sería sólo un conjunto de materiales tomados de Ezequiel 39. Varios indicios pueden ayudarnos en esta tarea. En primer lugar, la imagen de la espada de Cristo ya fue utilizada en el Apocalipsis en la carta a Pérgamo: ¿no sería ella una metáfora para designar la Palabra de Dios, como acontece en el texto célebre de Heb 4,12-13? En segundo lugar, hay que observar que los reyes de la tierra reaparecen en la Jerusalén celeste: Ap 21,24 los menciona entrando en la Ciudad. ¿Acaso esto no implica que sean reconciliados con Dios? Parece, entonces, que podemos interpretar el simbolismo de la manducación por parte de las aves, de los cadáveres de los enemigos muertos por la espada de Cristo, como una asimilación al cuerpo de la Iglesia. De hecho, la nutrición es un fenómeno de asimilación.

30. Cf. la reflexión muy justa de Feuillet: "En el Apocalipsis las imágenes militares y duras, aparentemente contrarias al espíritu del evangelio, vienen del Antiguo Testamento; son debidas a la voluntad del autor de enfatizar el cumplimiento de los oráculos antiguos; ellas no deben engañarnos en absoluto" ("Moisson", II, 228).
Cuando como la carne de un animal, ésta se hace parte de mi propio cuerpo. Si las aves del cielo simbolizan a los cristianos (ya que vuelan en el cielo), entonces el banquete puede significar simbólicamente una asimilación de los reyes de la tierra por parte de las aves, o sea su incorporación al cuerpo de la Iglesia. Varios intérpretes antiguos del Apocalipsis ya lo habían comprendido de esta manera: Ticonio en el siglo IV y Primasio en el siglo VI. ${ }^{31}$ Además, encontramos una confirmación de esta interpretación en la visión de Pedro en el capítulo 10 de los Hechos de los Apóstoles: los animales impuros que Pedro debe matar y comer simbolizan a los paganos (impuros según la ley de Moisés) que van a entrar en la Iglesia en la persona de Cornelio y de sus compañeros. ${ }^{32}$

\section{El papel de la Iglesia en la venida de Cristo}

Hagamos ahora una pregunta importante: ¿cuál es el papel de la Iglesia en la venida de Cristo? ¿Por qué el Apocalipsis distingue entre una venida de Cristo para las iglesias y una venida de Cristo para los pecadores? La respuesta no es inmediatamente visible, pero no deja espacio a la duda: por razón del papel que la Iglesia tiene en la conversión y la salvación de los pecadores. Este papel parece ser el contenido esencial del librito que el ángel poderoso entrega a Juan en el capítulo 10 y es más desarrollado en el capítulo 11 en la historia de los dos testigos. En este capítulo, el simbolismo de los dos testigos representa a la Iglesia que da testimonio de Cristo delante de las naciones. De hecho, ellos son comparados a candeleros, simbolismo eclesiológico según la visión inaugural del capítulo $1 .{ }^{33}$ Ellos son dos, no por ser parte de las siete Iglesias, sino por ra-

31. Cf. el fragmento del comentario perdido de Ticonio trasmitido por Beda el Venerable: "Hanc coenam Tychonius sic exponit: Omni tempore comedit Ecclesia carnes inimicorum suorum, dum comeditur ab eis, satiabitur autem in resurrectione de eorum carnali opere vindicata" (cf. BeDA, Explanatio Apocalypsis, PL 93, 191). Cf. también el comentario de Primasio: "Si quid enim manducamus, in corpus nostrum trajicimus" (Commentaria in Apocalypsim, PL 68, 913).

32. Ofrecemos una argumentación más desarrollada de esta interpretación en nuestro artículo "L'adoration dans l'Apocalypse", Ile partie, Aletheia 19 (2001) 152-157.

33. El Apocalipsis menciona candeleros solamente en la visión inaugural y en 11,4, lo que nos invita a aproximar los dos textos. No menciona candeleros en el cielo y tampoco en la Jerusalén celeste, lo que muestra que el candelero tiene como finalidad irradiar la luz de Cristo para el beneficio de las naciones, como vemos en Mt 5,14-16. 
zón de la exigencia conocida de Dt 19,15: es necesario tener por lo menos dos testigos para que un testimonio sea jurídicamente válido. Ellos están vestidos de sayal, lo que simboliza el carácter penitencial de su predicación, trazo tradicional de la predicación cristiana. ${ }^{34}$ Además, son también comparados simbólicamente con Moisés y Elías. Como lo dice Beale:

Los dos testigos representan el conjunto de la comunidad de fe cuya función primera es ser testigo profético. Así como Juan Bautista no era una reaparición literal de Elías sino que vino "en el espíritu y el poder de Elías" (LC 1,17), del mismo modo los dos testigos no son Moisés y Elías reencarnados (...). Ellos son llamados candeleros porque su palabra debe arder como una lámpara, así como la palabra de Elías ardía como una lámpara (Sir 48,1) y la de Juan Bautista "era como una lámpara que arde y alumbra" (Jn $5,35) .35$

Los dos testigos siguen perfectamente las huellas de Cristo: como Cristo, predican la penitencia y la conversión; como él, permanecen invulnerables durante el tiempo de su predicación; 36 como él, son muertos después del final de su misión; como él, son resucitados por Dios y suben para el cielo en la nube. En aquel momento tiene lugar un terremoto que destruye la décima parte de la ciudad y mata a 7.000 personas. Estas proporciones son evidentemente simbólicas, como lo son todos los números en el Apocalipsis; son una inversión significativa de 1 Re 19,17-18. En este trecho del Antiguo Testamento, Dios promete a Elías la sobrevivencia de un resto de 7.000 personas que no doblaron sus rodillas delante de Baal y tampoco lo besaron (o sea, que no se comprometieron con la idolatría generalizada). Al contrario, en Ap 11,13, todos los habitantes de la tierra parecen convertirse, 37 salvo un núcleo de irreductibles, un "anti-resto" de un

34. De hecho, la predicación de Juan Bautista era penitencial, la de Jesús también (cf. Mc 1,15). Fue también el caso de la predicación de Pedro el día de Pentecostés y de la de Pablo en Atenas (Hch 17), caso único de una predicación de Pablo a paganos cuyo discurso tenemos en sustancia.

35. G. K. BEALE, The Book of Revelation. A Commentary on the Greek Text, NIGTC, Eerdmans - Grand Rapids - 1999, 573.

$$
\text { 36. Cf. Jn 7,30; 8,20. }
$$

37. "Los supervivientes, presa de espanto, dieron gloria al Dios del cielo" $(11,13 \mathrm{~b})$. Encontramos una expresión semejante en Dn 4,37 (Theod.), donde Nabucodonosor, vuelto de su locura, da gloria al Dios del cielo. El temor de Dios es a menudo en el Antiguo Testamento el signo del arrepentimiento (Jos 7,19; Jr 13,16; 1 Sam 6,5). décimo, ${ }^{38}$ de 7.000 personas que perecen en el terremoto porque no se arrepintieron de sus pecados (cf. 9,20-21). Así, la conversión de los habitantes de la tierra, que no pudo ser lograda por las plagas de las trompetas, es lograda por el testimonio y el sacrificio de los dos testigos. 39

Una vez que entendemos correctamente el episodio de los dos testigos, el papel de la Iglesia aparece en toda su fuerza. La Iglesia es un candelero que tiene como misión irradiar la luz de Cristo en el mundo. Por su predicación, ella debe conducir a los paganos a la conversión y a la salvación. Esta predicación la conduce hasta la cruz, pero también hasta la resurrección y la asunción siguiendo a Cristo. En resumen, la Iglesia no tiene otro camino sino el que Cristo siguió.

Aunque el vocabulario de la venida esté ausente del capítulo 11 del Apocalipsis, parece justificado, sin embargo, hablar aquí de venida anticipada de Cristo para las naciones, pero entendiendo que se trata de una venida mediatizada por la predicación de la Iglesia:

Por el anuncio del evangelio a las naciones, los cristianos son los instrumentos de la venida anticipada del Hijo del Hombre para invitar a la conversión. Entonces, el Hijo del Hombre viene también de manera anticipada en medio de las naciones, pero de un modo distinto que a las iglesias: viene por el ministerio de los predicadores evangélicos. Por una parte, viene a las iglesias por sus cartas; por otra parte, viene a las naciones por la misión de los cristianos que predican su evangelio. 40

Esta misión de los cristianos para las naciones nos permite entender la naturaleza, enigmática a primera vista, del castigo anunciado a la Iglesia de Éfeso, en caso de que ella no se convierta:

38. De hecho, en el Antiguo Testamento, la proporción de un décimo se refiere al resto de Israel, como vemos en Is 6,13 y en Am 5,3. El Apocalipsis retoma la imagen, pero la aplica de manera inversa a los habitantes de la tierra: no es un décimo que es preservado sino un décimo que perece.

39. Cf. BAUCKHAM, Theology, 86-87. Es verdad que este último punto no es aceptado por todos los comentaristas. Algunos, como Beale, tienen una comprensión más pesimista y no piensan que los supervivientes del terremoto se convierten. A pesar de sus objeciones, pensamos sin embargo que es la interpretación mejor. De hecho, los sobrevivientes hacen exactamente lo que el ángel exhorta a los habitantes de la tierra a hacer en 14,7: "Teman a Dios y denle gloria, porque ha llegado la hora de su juicio; adoren al que hizo el cielo y la tierra, el mar y los manantiales de agua".

40. Comblin, Christ, 65 
Date cuenta, pues, de dónde has caído, arrepiéntete y vuelve a tus primeras obras. Si no, vengo a ti y cambiaré de su lugar tu candelero, si no te arrepientes. $(2,5)$

Si el candelero de Éfeso viene a extinguirse, ya no será apto para difundir la luz de Cristo delante de las naciones. No sirviendo más para nada, será entonces sustituido por otro. Comprendemos también la severidad de Cristo contra los cristianos de Pérgamo que siguen la doctrina de Balaán o son discípulos de Jezabel en Tiatira. Balaán y Jezabel eran dos personajes del Antiguo Testamento que se opusieron violentamente a Moisés y Elías, precisamente los dos cuyas figuras son llevadas por los dos testigos. Esto significa que si las Iglesias de Pérgamo y Tiatira se dejan seducir, ya no podrán cumplir su papel profético.

De modo general, entonces, la Iglesia no tiene que esperar la venida de Cristo solamente en la oración, con la preocupación de no ser sorprendida, y abandonando el resto de los hombres a su suerte. No, Cristo quiere que la Iglesia trabaje durante este tiempo, continuando su misión en el espacio y en el tiempo. El Apocalipsis presenta la peregrinación de la Iglesia en la tierra como un nuevo éxodo. ${ }^{41} \mathrm{Sin}$ embargo, existe una diferencia capital entre el primer éxodo de la historia (la salida de Israel de Egipto) y el nuevo éxodo de la Iglesia: el pueblo de Israel entró solo en la Tierra Santa, pero la Iglesia no debe entrar sola en la Jerusalén celeste; debe entrar llevando con ella a las naciones.

\section{Venidas de Cristo y venida del Padre}

Si el Apocalipsis presenta al Padre y a Cristo (aunque no al Espíritu Santo) como sujetos del verbo "venir", podemos preguntarnos ¿qué relación se establece entre estas venidas? Hemos visto que las venidas de Cristo son múltiples: Cristo viene a la tierra de manera escondida, para ejercer el juicio de modo anticipado en las Iglesias en vista de su conversión, y también en las naciones a través de la mediación de las Iglesias, también en vista de la conversión. La venida final de Cristo es la de la parusía, pero la venida del Padre parece referirse solamente a una venida final para el juicio. Esta venida del Padre es presentada indirectamente en 11,17, cuando suene la séptima trompeta, en la expresión "Aquel que es y que era" (sin el tercer miembro "y que va a venir") para significar que la venida del Pa-

\footnotetext{
41. Sobre esto, ver BAUCKHAM, Theology, 70-72.
}

dre no es más futura sino presente. El juicio de Dios es presentado de nuevo al final de los mil años en 20,11-15 con la comparecencia de los muertos ante el trono de Dios. Es cierto que el Apocalipsis no dice explícitamente que es Dios el que juzga a los muertos; sin embargo, el uso de los verbos en pasivo (unos libros fueron abiertos, los muertos fueron juzgados) sugiere que es el caso. Después de este juicio, el Apocalipsis habla por primera vez de la morada de Dios entre los hombres $(21,3)$. En otras palabras, Dios que reinaba en el cielo, mientras la tierra estaba bajo el imperio de la Bestia, puede ahora reinar sobre la tierra. En este sentido, podríamos decir que las venidas de Cristo son ordenadas a la venida del Padre.

\section{8. "Vengo pronto"}

Hemos visto que Cristo afirma cinco veces que viene pronto. Veamos ahora las otras tres que se encuentran en el capítulo 22:

Mira, vengo pronto. Dichoso el que guarde las palabras proféticas de este libro. $(22,7)$

Mira, vengo pronto y traigo mi recompensa conmigo para pagar a cada uno según sus obras. $(22,12)$

Dice el que da testimonio de todo esto: "Si, vengo pronto". ¡Amén! ¡Ven, Señor Jesús! $(22,20)$

El anuncio de 22,7 es inmediatamente seguido por la sexta bienaventuranza que proclama feliz al que guarda la profecía de este libro. Esta bienaventuranza constituye claramente una inclusión con la primera, al inicio del libro:

Dichoso el que lea y los que escuchen las palabras de esta profecía y guarden lo escrito en ella, porque el tiempo está cerca. $(1,3)$

Ahora, la primera mención de la venida de Cristo en 1,7 es muy semejante:

Miren, viene acompañado de nubes

Más fuertemente que la primera bienaventuranza, la sexta debe ser, entonces, considerada a la luz de la venida próxima de Cristo.

El anuncio de 22,12 es como un eco de la carta a Tiatira en 2,23:

Así sabrán todas las Iglesias que yo soy el que sondea los riñones y los corazones, y yo les daré a cada uno de ustedes según sus obras. 
El tema de las obras tiene un lugar importante en las cartas a las Iglesias, con doce ocurrencias. Ahí, Cristo declara conocer las obras de cada una de las Iglesias. Éfeso debe volver a sus primeras obras $(2,5)$; las últimas obras de Tiatira abundan $(2,19)$, pero las obras de Sardes no están llenas a sus ojos $(3,2)$. El anuncio del versículo 22,12, entonces, es una exhortación a las Iglesias para ser más fructuosas hasta la vuelta de Cristo.

Finalmente, el anuncio del versículo 22,20 constituye la última palabra de Cristo en el Apocalipsis, la que ofrece la última luz.

Ahora, ¿cómo comprender este "pronto”? Ya son casi 2.000 años desde que el Apocalipsis fue escrito y la parusía todavía no aconteció. ¿Acaso debemos tomar en serio este "pronto”? ¿O tal vez deberíamos pensar que Juan se equivocó, con la ilusión de que la parusía acontecería dentro de un plazo de algunos años?

En realidad, el Apocalipsis no ofrece ningún indicio cronológico sobre la fecha del regreso de Cristo. Cristo ya había dicho abiertamente en el Evangelio que nadie conoce el día y la hora de su regreso. Pienso, entonces, que debemos renunciar francamente a cualquier interpretación cronológica a favor de una interpretación teológica. ¿Qué significa esto? Naturalmente, podríamos decir que un plazo determinado, por largo que sea (incluso millares de años) es poco en comparación con la eternidad. Es cierto; este argumento es correcto a nivel teológico, pero aquí se trata de otra cosa. El adverbio "pronto" tiene una connotación parenética. Al insistir sobre el hecho de que Cristo regresa pronto, el Apocalipsis invita a los cristianos a vivir en esta luz, a ordenar sus vidas en esta perspectiva. Este es precisamente el punto clave de este anuncio: los cristianos deben vivir como si Cristo regresase realmente muy pronto, aceptando al mismo tiempo no saber cuándo regresará. El anuncio de la proximidad del retorno de Cristo intenta entonces mantener a los cristianos en estado de vigilia.

El Apocalipsis no invita solamente a los cristianos a esperar el regreso de Cristo, sino que los invita también a pedirlo. El Espíritu Santo conduce a la Iglesia para que pida el regreso de Cristo, sin duda porque es una manera excelente para que la Iglesia se prepare al regreso del Esposo. Al repetir frecuentemente Marána thá, la Iglesia se acuerda de la proximidad del retorno de Cristo y se renueva en la vigilia. El deseo del Esposo es encontrar a la Esposa deseando ardientemente su regreso.

Alain-MARIE DE LASSUS, CSJ fr.alain-marie@stjean.com

Saint Jodard, Francia 